\title{
Sensitive Spectrophotometric Determination of Phosphate Using Silica-Gel Collectors
}

\author{
Masahiro NAGAI, ${ }^{* \dagger}$ Masahito SugIYAMa, $* *$ and Toshitaka HorI** \\ *Faculty of Human Environments Studies, The University of Human Environments, \\ 6-2, Kamisanbonmatsu, Motojuku-cho, Okazaki 444-3505, Japan \\ **Graduate School of Human and Environmental Studies, Kyoto University, \\ Yoshida-nihonmatsu-cho, Sakyo-ku, Kyoto 606-8501, Japan
}

\begin{abstract}
Phosphate, 3 - $10 \mathrm{nmol}$, in $1 \mathrm{dm}^{3}$ of natural-water samples was quantitatively collected along with $10 \mu \mathrm{mol}$ of Fe(III) ion onto a silica-gel collector in the $\mathrm{pH}$ range of $5.4-6.2$. The amount of $\mathrm{Fe}(\mathrm{III})$ ion needed was limited to such a low level that the Pyrocatechol Violet method could be applied without removing the $\mathrm{Fe}$ (III) ion, providing a superior determination method for phosphate. Surface-water samples of the north basin of Lake Biwa and the Tanabe Bay in the Wakayama prefecture were selected as being representative of natural water with extremely low phosphate concentrations, and were found to have phosphate concentrations of 3.68 and $4.31 \mathrm{nmol} \mathrm{dm}^{-3}$, respectively.
\end{abstract}

(Received June 30, 2003; Accepted November 13, 2003)

\section{Introduction}

Phosphate is an essential substance for the growth and reproduction of living organisms, and one of the main controlling factors for the characteristics of streams, rivers, lakes, and oceans. Improvements in the sensitivity and precision of phosphate analysis and simplification of the analytical procedure should significantly benefit various research fields, such as limnology, oceanography, and environmental chemistry. Currently, there are several standard methods that satisfy such demands. One of the most popular methods is the molybdenum blue reaction with coexisting antimony, proposed by Murphy and Riley, ${ }^{1}$ which has been applied not only to seawater, but also to lake water and to evaluating the quality of water and wastewater. ${ }^{2}$ This method is superior both in sensitivity and precision (detection limit of 0.3 $\mu \mathrm{mol} \mathrm{dm}-3$, relative standard deviation of $2 \%$ at $7 \mu \mathrm{mol} \mathrm{dm}{ }^{-3}$ ), and the analysis can be automated with the flow-injection method. ${ }^{3}$

However, there is still a need to improve the method for determining phosphate in natural water by one or two orders in sensitivity, since the dissolved phosphate concentrations of most natural-water samples collected from the headstreams of rivers, the surface of lakes during summer stratification, or the surface of pelagic water are significantly below the detection limit of the conventional determination methods. For example, in the surface water of lakes and oceans, where natural purification, such as the removal of nutritious phosphate by phytoplanktons proceeds actively, phosphate concentrations are often decreased

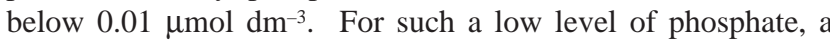
more sensitive method has been expected to substantiate limnologically and oceanographically the processes of natural purification.

† To whom correspondence should be addressed.
In the past, many methods have been proposed for determination of phosphate in natural water. For example, Ishibashi and Tabushi ${ }^{4}$ proposed a method that combines the preconcentration of phosphate using hydrated iron oxides as adsorbents and the solvent extraction of phosphomolybdate to butyl acetate, and succeeded in determinating phosphate in seawater at concentrations of $0.05-0.1 \mu \mathrm{mol} \mathrm{dm}{ }^{-3}$. Hori et al. ${ }^{5}$ proposed an indirect determination method in which phosphomolybdate is first extracted in a mixed solvent of methyl isobutyl ketone and cyclohexane. Then, the molybdenum in the organic solvent is quantified by the Pyrocatechol Violet method. This analytical method improved

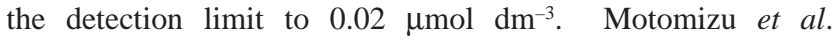
attempted to improve the sensitivity according to a different principle. ${ }^{6,7}$ In their method, the phosphomolybdate produced in $5-100 \mathrm{~cm}^{3}$ of sample water is made to form an ion-associate with cationic dyes, such as Ethyl Violet ${ }^{6}$ or Malachite Green, $^{7}$ and then extracted in a solvent. They achieved a detection limit of $0.003 \mu \mathrm{mol} \mathrm{dm}{ }^{-3}$ with this method.

In this study, we found that phosphate in a sample solution can be collected by silica gel in the presence of a small amount of $\mathrm{Fe}(\mathrm{III})$ ion. Under the most appropriate conditions, the phosphate can be quantitatively adsorbed onto silica gel at $\mathrm{pH}$ $5.4-6.2$ with $10 \mu \mathrm{mol}$ of $\mathrm{Fe}$ (III) ion. Thus, this method can be used to effectively preconcentrate phosphate in natural water, such as lake water and seawater. By combining this preconcentration method with the Pyrocatechol Violet method, ${ }^{5}$ it is possible to quantify phosphate within concentrations of $0.003-0.01 \mu \mathrm{mol} \mathrm{dm}{ }^{-3}$.

\section{Experimental}

Reagents

A 11:9 (v/v) methyl isobutyl ketone/cyclohexane-mixed solvent, a $0.2 \%$ pyrocatechol sulfonphthalein (Pyrocatechol 
Violet) solution, and a $0.5 \%$ methyltrioctylammonium chloride (Capriquat)-ethanol solution were prepared according to Hori et al. ${ }^{5}$

A $0.12 \mathrm{~mol} \mathrm{dm}^{-3}$ sodium molybdate solution, a $0.1000 \mathrm{~mol}$ $\mathrm{dm}^{-3}$ potasium dihydrogen phosphate standard solution, and a $0.1 \mathrm{~mol} \mathrm{dm}^{-3}$ ferric chloride solution were also used. Artificial seawater was prepared following a method of Lyman and Fleming. ${ }^{8}$

A dispersed silica gel solution was prepared in the following manner. A 7.10-g dose of $\mathrm{Na}_{2} \mathrm{SiO}_{3} \cdot 9 \mathrm{H}_{2} \mathrm{O}$ was dissolved in 40 $\mathrm{cm}^{3}$ of distilled water, to which $5 \mathrm{~cm}^{3}$ of conc. $\mathrm{HCl}$ was added and mixed thoroughly. The solution was continuously mixed while $\mathrm{NaOH}$ solution was added in drops to gradually increase the $\mathrm{pH}$ to 8 . The viscosity of the solution gradually increased with the $\mathrm{pH}$ to attain a starch-like texture. This silica gel was separated from the solution by centrifugation, washed 5 times with distilled water, dispersed in distilled water and diluted to $50 \mathrm{~cm}^{3}$. For every phosphate sample solution, $1 \mathrm{~cm}^{3}$ of this dispersed silica gel solution was used.

\section{Standard procedures}

Phosphate in natural water is collected using silica gel in the presence of $\mathrm{Fe}(\mathrm{III})$ ion. Since the $\mathrm{Fe}(\mathrm{III})$ ion needed for collection is kept at a low level, it is possible to apply the Pyrocatechol Violet method, ${ }^{5}$ which enables the achievement of a superior determination method for phosphate. Below is an outline of the standard analytical procedures.

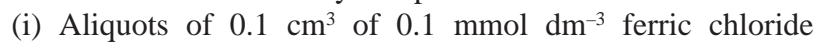
solution and $1 \mathrm{~cm}^{3}$ of the dispersed silica gel solution are added to $1 \mathrm{dm}^{3}$ of a water sample previously filtered through a nuclepore filter with a pore size of $0.40 \mu \mathrm{m}$. The solution is mixed thoroughly for $1 \mathrm{~h}$ after adjusting the $\mathrm{pH}$ to $5.4-6.2$ with a $\mathrm{HCl}$ or $\mathrm{NaOH}$ solution. Then, the precipitate, which consists of silica gel and phosphate adsorbed onto the gel with Fe(III) ion, is collected by filtration through the same filter as mentioned above. The phosphate in the precipitate on the filter is dissolved with $3.5 \mathrm{~cm}^{3}$ of heated $6 \mathrm{~mol} \mathrm{dm}^{-3} \mathrm{HCl}$, and collected in a $50-\mathrm{cm}^{3}$ centrifuge tube with a ground-in stopper. The filtrate and the wash liquids are combined and diluted with distilled water to $c a .35 \mathrm{~cm}^{3}$. This $\mathrm{HCl}$ solution, which contains phosphate, is analyzed in the following step: (ii) the sample solution obtained as mentioned above is mixed with $3.5 \mathrm{~cm}^{3}$ of a $0.12 \mathrm{~mol} \mathrm{dm}^{-3}$ sodium molybdate solution. This solution, in which phosphomolybdate is formed, is mixed with $7 \mathrm{~cm}^{3}$ of a 11:9 (v/v) methyl isobutyl ketone/cyclohexane-mixed solvent and shaken vigorously for $5 \mathrm{~min}$ for extracting the phosphomolybdate. After separation of the organic and aqueous layers, $5 \mathrm{~cm}^{3}$ of the organic layer is transferred into a $10-\mathrm{cm}^{3}$ centrifuge tube with a ground-in stopper. Then, $2.5 \mathrm{~cm}^{3}$ of $1 \mathrm{~mol} \mathrm{dm}^{-3} \mathrm{NaOH}$ is added to the organic solution, and the mixture is shaken for $1 \mathrm{~min}$, followed by the addition of $1.5 \mathrm{~cm}^{3}$ of $2.5 \mathrm{~mol} \mathrm{dm}^{-3} \mathrm{HCl}, 1 \mathrm{~cm}^{3}$ of a $0.2 \%$ Pyrocatechol Violet solution, and $0.5 \mathrm{~cm}^{3}$ of a $0.5 \%$ Capriquat solution. The mixture is shaken again for $1 \mathrm{~min}$. After separation of the organic and aqueous layers, the absorbance of the organic layer in $1-\mathrm{cm}$ cell is measured at $545 \mathrm{~nm}$.

\section{Results}

\section{Calibration curve}

After $35 \mathrm{~cm}^{3}$ portions of $0.6 \mathrm{~mol} \mathrm{dm}{ }^{-3} \mathrm{HCl}$ were transferred into a $50-\mathrm{cm}^{3}$ centrifuge tube with a ground-in stopper, $2.5,5$, 7.5 , and $10 \mathrm{nmol}$ portions of phosphate were added to them. Step (ii) of the standard procedures was applied to the solutions. (a)

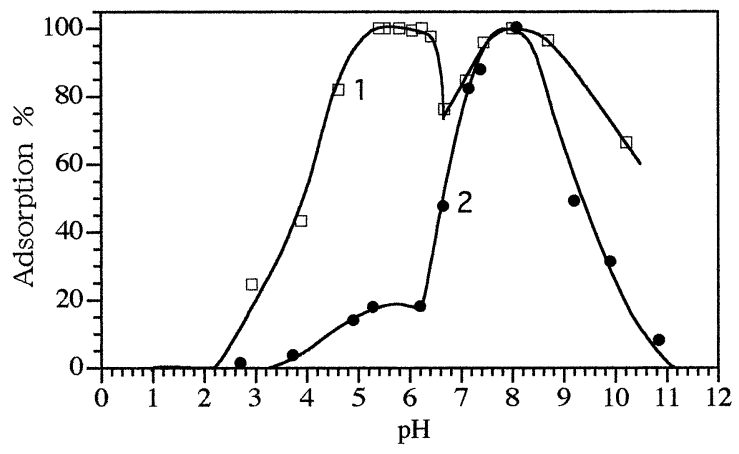

(b)

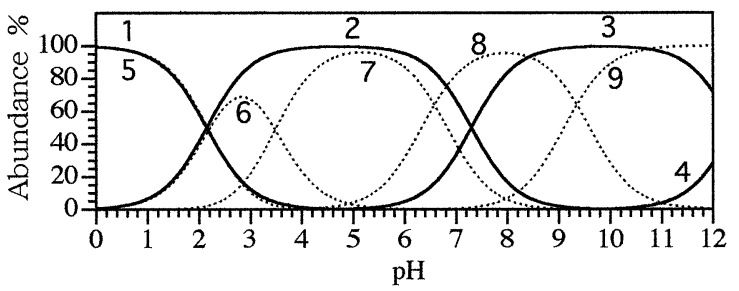

Fig. 1 (a) Adsorption curves of phosphate in the presence of Fe(III) ion. The adsorptions of $20 \mathrm{nmol}$ of phosphate in $1 \mathrm{dm}^{3}$ of water with (curve 1) and without (curve 2) the addition of silica gel were compared in the presence of Fe(III) ion. (b) Formation curves for the chemical species of phosphate and Fe(III) ions. The chemical species of phosphate ion (solid lines) $\left[1, \mathrm{H}_{3} \mathrm{PO}_{4} ; 2, \mathrm{H}_{2} \mathrm{PO}_{4}^{--} ; 3, \mathrm{HPO}_{4}^{2-} ; 4\right.$, $\left.\mathrm{PO}_{4}{ }^{3-}\right]$ and $\mathrm{Fe}(\mathrm{III})$ ion (dashed lines) $\left[5, \mathrm{Fe}^{3+} ; 6, \mathrm{FeOH}^{2+} ; 7, \mathrm{Fe}(\mathrm{OH})_{2}{ }^{+}\right.$; $\left.8, \mathrm{Fe}(\mathrm{OH})_{3}(\mathrm{aq}) ; 9, \mathrm{Fe}(\mathrm{OH})_{4^{-}}\right]$are given as a function of the $\mathrm{pH}$. The equilibrium constants used in the calculations were, for phosphate ion, $\log K_{\mathrm{a} 1}=-2.2, \log K_{\mathrm{a} 2}=-7.2$, and $\log K_{\mathrm{a} 3}=-12.3$, and for $\mathrm{Fe}$ (III) ion, $\log K_{\mathrm{a} 1}=-2.19, \log K_{\mathrm{a} 2}=-3.48, \log K_{\mathrm{a} 3}=-6.33$, and $\log K_{\mathrm{a} 4}=$ -9.6 (Stumm and Morgan). ${ }^{9}$

The values of the absorbance measured against a reagent blank were 0.209 for a solution whose content of phosphate was 2.5 nmol, 0.428 for $5 \mathrm{nmol}$ of phosphate, 0.632 for $7.5 \mathrm{nmol}$, and 0.836 for $10 \mathrm{nmol}$. The slope of the linear calibration curve drawn from these values was $0.0838 \mathrm{nmol}^{-1}$ and the correlation coefficient was 0.9999 .

After distilled water, and 2.5 and $10 \mathrm{nmol} \mathrm{dm}^{-3}$ potassium dihydrogen phosphate solutions were prepared, steps (i) and (ii) of the standard procedures were applied to $1 \mathrm{dm}^{3}$ portions of these solutions. The values of the absorbances measured against the same reagent blank as above were -0.013 for a sample solution containing no phosphate, 0.218 for the content of $2.5 \mathrm{nmol}$ of phosphate, and 0.838 for $10 \mathrm{nmol}$. Comparing these results with those mentioned above for the same contents of phosphate, they were in good agreement (their differences were 0.009 for $2.5 \mathrm{nmol}$ of phosphate, 0.002 for $10 \mathrm{nmol}$, and -0.013 for no phosphate). This shows that phosphate is quantitatively collected in step (i), and that the calibration curve can be drawn only by applying step (ii) without the preconcentration procedures of step (i) .

\section{Determination of phosphate in natural waters}

Two samples were taken from the surface water of the north basin of Lake Biwa (depth 73 m, sampled in Dec. 1999) and the Tanabe Bay in Wakayama prefecture (depth $30 \mathrm{~m}$, sampled in Aug. 1999), and analyzed twice $(n=2)$ according to the standard procedures. The concentrations of phosphate in the lake water were 3.67 and $3.68 \mathrm{nmol} \mathrm{dm}^{-3}$, and those in the seawater were 4.30 and $4.32 \mathrm{nmol} \mathrm{dm}^{-3}$. 


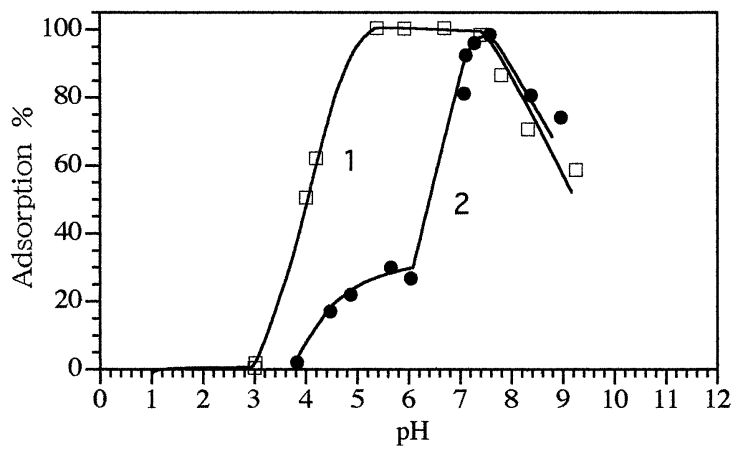

Fig. 2 Adsorption curves of phosphate in seawater in the presence of $\mathrm{Fe}(\mathrm{III})$ ion. The adsorptions of $20 \mathrm{nmol}$ of phosphate in $1 \mathrm{dm}^{3}$ of artificial seawater with (curve 1) and without (curve 2) the addition of silica gel were compared in the presence of $\mathrm{Fe}(\mathrm{III})$ ion.

\section{Discussion}

\section{The adsorption curves of phosphate}

Curve 1 in Fig. 1a is the adsorption curve of phosphate in a 20 nmol $\mathrm{dm}^{-3}$ potassium dihydrogen phosphate solution onto silica gel in the presence of Fe(III) ion. This adsorption curve has two local maxima. The curve begins to rise at around $\mathrm{pH} 3$ and reaches the first maximum with a constant value at $\mathrm{pH} 5.4-6.2$. It then drops off to $80 \%$ of the peak value at $\mathrm{pH} 6.5$, and then rises again above $\mathrm{pH} 6.5$ to reach the second maximum at $\mathrm{pH} 8$.

For a comparison, the adsorption curve of phosphate onto silica gel without $\mathrm{Fe}$ (III) ion was investigated. It was found that phosphate was scarcely adsorbed onto silica gel alone. Next, the adsorption of phosphate to iron hydroxide (curve 2) was studied. The rate of adsorption was around $20 \%$ in the $\mathrm{pH}$ range of $3-6.2$, increased above $\mathrm{pH} 7$, and reached a maximum at $\mathrm{pH}$ 8. This adsorption curve resembled curve 1 in the $\mathrm{pH}$ range of $7-10$. This indicates that the adsorption of phosphate at $\mathrm{pH} 7-10$ can be attributed to the adsorption solely onto iron hydroxide, but that the presence of both $\mathrm{Fe}(\mathrm{III})$ ion and silica gel is necessary for adsorption at pH $5.4-6.2$.

The adsorption curve was obtained for artificial seawater in a similar manner (Fig. 2), and the phosphate could be collected effectively by adsorption onto silica gel in the presence of $\mathrm{Fe}(\mathrm{III})$ ion, even for seawater samples. Curve 1 in Fig. 2 indicates that phosphate in seawater is quantitatively adsorbed at $\mathrm{pH} 5.4-7.4$. This $\mathrm{pH}$ range was wider than the above range for fresh water. For a comparison, curve 2 in Fig. 2 shows the adsorption curve of phosphate to iron hydroxide. Almost the same as that for fresh-water samples, the local maximum of the adsorption curve was reached at $\mathrm{pH} 8$.

It is concluded that by using silica gel as collectors in the presence of $\mathrm{Fe}(\mathrm{III})$ ion, phosphate can be adsorbed quantitatively over a relatively wide $\mathrm{pH}$ range of $5.4-6.2$ for both fresh-water and seawater samples.

\section{The desorption curve of phosphate}

Figure 3 shows the desorption curve of phosphate collected on silica gel in the presence of $\mathrm{Fe}$ (III) ion, along with the adsorption curve for a comparison. The adsorption and desorption of phosphate was irreversible for the $\mathrm{pH}$, and stronger acidity was necessary for the desorption. However, as can be seen from the figure, phosphate is desorbed quantitatively into the aqueous solution below $\mathrm{pH} 1$.

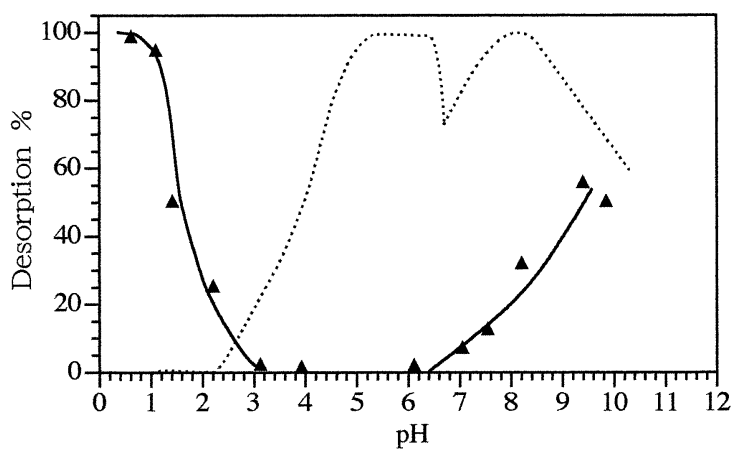

Fig. 3 Desorption curve of phosphate from silica gel in the presence of $\mathrm{Fe}(\mathrm{III})$ ion. Phosphate $(2 \mu \mathrm{mol})$, which had been adsorbed onto silica gel in the presence of Fe(III) ion, was desorped into the solution by varying the $\mathrm{pH}$. For a comparison, the adsorption curve (dashed line) is superimposed.

\section{Chemical form of the phosphate adsorbed}

Although the adsorption mechanism for the three-component system of phosphate-Fe(III)-silica gel has been left unsolved, it is ensured unambiguously in the preceding paragraphs that phosphate ion, even at extremely low concentrations, is collected quantitatively in the presence of both $\mathrm{Fe}(\mathrm{III})$ ion and silica gel. The most probable mechanisms are: (1) chemical species of phosphate-Fe(III) formed in the aqueous phase are adsorbed on the silica gel, and (2) phosphate ions in the aqueous phase are adsorbed on the silica gel containing Fe(III) ion. In the present paper, we can say that mechanism (1) is anticipated from the similarity between the adsorption curves of phosphate ion (Fig. 1a) and the distribution curves of phosphate and $\mathrm{Fe}(\mathrm{III})$ ions (Fig. 1b).

Figure $1 \mathrm{~b}$ shows the distribution of the chemical forms of phosphate and $\mathrm{Fe}$ (III) ions as functions of the $\mathrm{pH}$. Among the possible combinations of the chemical forms of phosphate ion $\left(\mathrm{H}_{3} \mathrm{PO}_{4}, \mathrm{H}_{2} \mathrm{PO}_{4}^{-}, \mathrm{HPO}_{4}{ }^{2-}, \mathrm{PO}_{4}{ }^{3-}\right)$ and $\mathrm{Fe}(\mathrm{III})$ ion $\left(\mathrm{Fe}^{3+}, \mathrm{FeOH}^{2+}\right.$, $\left.\mathrm{Fe}(\mathrm{OH})_{2}{ }^{+}, \mathrm{Fe}(\mathrm{OH})_{3}(\mathrm{aq}), \mathrm{Fe}(\mathrm{OH})_{4}^{-}\right)$, the combinations of the dominant species are (i) $\mathrm{H}_{3} \mathrm{PO}_{4}$ and $\mathrm{Fe}^{3+}$ at $\mathrm{pH}<2.2$ (curves 1 \& 5), (ii) $\mathrm{H}_{2} \mathrm{PO}_{4}^{-}$and $\mathrm{FeOH}^{2+}$ (curves $2 \& 6$ ) at $\mathrm{pH}=2.2-3.5$, (iii) $\mathrm{H}_{2} \mathrm{PO}_{4}^{-}$and $\mathrm{Fe}(\mathrm{OH})_{2}{ }^{+}$(curves $2 \& 7$ ) at $\mathrm{pH}=3.5-6.3$, (iv) $\mathrm{H}_{2} \mathrm{PO}_{4}^{-}$and $\mathrm{Fe}(\mathrm{OH})_{3}(\mathrm{aq})$ (curves $2 \& 8$ ) at $\mathrm{pH}=6.3-7.2$, (v) $\mathrm{HPO}_{4}{ }^{2-}$ and $\mathrm{Fe}(\mathrm{OH})_{3}(\mathrm{aq})$ (curves $3 \& 8$ ) at $\mathrm{pH}=7.2-9.6$, and (vi) $\mathrm{HPO}_{4}{ }^{2-}$ and $\mathrm{Fe}(\mathrm{OH})_{4}^{-}$(curves $3 \&$ 9) at $\mathrm{pH}>9.6$. As aforementioned, the adsorption of phosphate onto silica gel in the presence of $\mathrm{Fe}$ (III) ion occurs especially with an adsorption rate of over $50 \%$ in the $\mathrm{pH}$ range of $4-6.5$ (curve 1 in Fig. 1a). The combination of the chemical forms of phosphate and Fe(III) ions in this range, which may interact together, is the combination (iii) of $\mathrm{H}_{2} \mathrm{PO}_{4}^{-}$and $\mathrm{Fe}(\mathrm{OH})_{2}{ }^{+}$. The reaction product, therefore, is considered to be $\mathrm{H}_{2} \mathrm{PO}_{4} \cdot \mathrm{Fe}(\mathrm{OH})_{2}$ or $\mathrm{FePO}_{4}$. These are neutral species, and when phosphate and $\mathrm{Fe}$ (III) ions are present in high concentrations, the solubility product is easily exceeded and precipitation occurs. However, when the two are present only in extremely low concentrations and the solubility product is not exceeded, there is almost no precipitation present. When silica gel coexists as a third component in such a condition, $\mathrm{FePO}_{4}$ is collected onto the gel. This is in good agreement with the observation of the remarkable phosphate adsorption in the $\mathrm{pH}$ range of $5.4-6.2$ (curve 1 in Fig. 1a) in a mixed system of phosphate, Fe(III) ion, and silica gel.

The combinations of dominant species of phosphate and $\mathrm{Fe}(\mathrm{III})$ ions in the $\mathrm{pH}$ range of $6.5-9$ are (iv) $\mathrm{H}_{2} \mathrm{PO}_{4}^{-}$and 


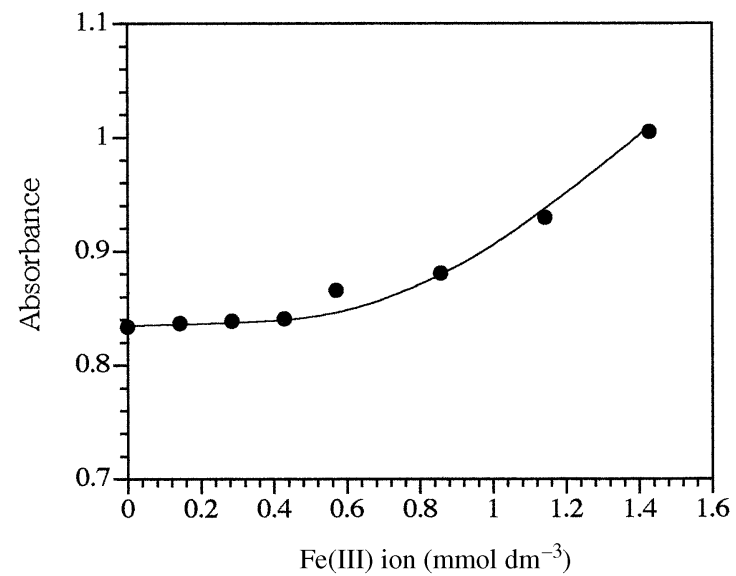

Fig. 4 Effect of $\mathrm{Fe}(\mathrm{III})$ ion on the Pyrocatechol Violet method. The method was applied to sample solutions in the $\mathrm{Fe}(\mathrm{III})$ ion concentration range of $0-1.43 \mathrm{mmol} \mathrm{dm}^{-3}$ and a constant phosphate concentration $\left(0.285 \mu \mathrm{mol} \mathrm{dm}{ }^{-3}\right)$. The absorbances at $545 \mathrm{~nm}$ were plotted against the $\mathrm{Fe}$ (III) ion concentrations.

$\mathrm{Fe}(\mathrm{OH})_{3}(\mathrm{aq})$ or $(\mathrm{v}) \mathrm{HPO}_{4}{ }^{2-}$ and $\mathrm{Fe}(\mathrm{OH})_{3}(\mathrm{aq})$. This implies that, in the absence of silica gel, the phosphate adsorbed onto iron hydroxide is either $\mathrm{H}_{2} \mathrm{PO}_{4}^{-}$or $\mathrm{HPO}_{4}{ }^{2-}$.

The effect of $\mathrm{Fe}(\mathrm{III})$ ion on phosphate determination

The Pyrocatechol Violet method was applied to samples with a constant phosphate concentration and varying $\mathrm{Fe}$ (III) ion concentrations (Fig. 4). Positive errors were observed at a $\mathrm{Fe}$ (III) ion concentration $\geq 0.5 \mathrm{mmol} \mathrm{dm}^{-3}$. Because the $\mathrm{Fe}$ (III) ion concentration is limited to $0.3 \mathrm{mmol} \mathrm{dm}^{-3}$ in the sample solution obtained in step (i) of the standard procedures, the
Pyrocatechol Violet method can be performed with high sensitivity without any negative effects from the Fe(III) ion.

\section{Acknowledgements}

We are grateful to the faculty members of the Center for Ecological Research, Kyoto University, and of the Seto Marine Biological Laboratory, Kyoto University, for the use of their observation facilities on Lake Biwa and Tanabe Bay. This work was supported in part by Grants-in-Aid for Scientific Research (Category: C-15550069) from the Ministry of Education, Culture, Sports, Science and Technology.

\section{References}

1. J. Murphy and J. P. Riley, Anal. Chim. Acta, 1962, 27, 31.

2. L. S. Clesceri, A. E. Greenberg, and R. R. Trussell, "Standard Methods for the Examination of Water and Wastewater", 1989, American Public Health Association, Washington.

3. A. Henriksen, Analyst, 1966, 91, 652.

4. M. Ishibashi and M. Tabushi, Japan Analyst, 1959, 8, 588.

5. T. Hori, Y. Kanada, and T. Fujinaga, Bunseki Kagaku, 1982, 31, 592.

6. S. Motomizu, T. Wakimoto, and K. Toei, Anal. Chim. Acta, 1982, 138, 329.

7. S. Motomizu, T. Wakimoto, and K. Toei, Talanta, 1984, 31, 235.

8. J. Lyman and R. H. Fleming, J. Mar. Res., 1940, 3, 134.

9. W. Stumm and J. J. Morgan, "Aquatic Chemistry", 1981, John Wiley \& Sons. 